\title{
Un recueil de 1626, comprenant trois ouvrages en rapport avec la thématique du temps
}

\section{Daniel Bornemann}

\section{(2) OpenEdition}

1 Journals

Édition électronique

URL : http://journals.openedition.org/rbnu/1428

DOI : $10.4000 /$ rbnu. 1428

ISSN : 2679-6104

\section{Éditeur}

Bibliothèque nationale et universitaire de Strasbourg

\section{Édition imprimée}

Date de publication : 1 novembre 2015

Pagination : 110-115

ISBN : 9782859230616

ISSN : 2109-2761

\section{Référence électronique}

Daniel Bornemann, « Un recueil de 1626, comprenant trois ouvrages en rapport avec la thématique du temps », La Revue de la BNU [En ligne], 12 | 2015, mis en ligne le 01 mars 2020, consulté le 11

décembre 2020. URL : http://journals.openedition.org/rbnu/1428; DOI : https://doi.org/10.4000/rbnu. 1428

\section{(c) (ஒ)(}

La Revue de la BNU est mise à disposition selon les termes de la Licence Creative Commons Attribution - Pas d'Utilisation Commerciale - Partage dans les Mêmes Conditions 4.0 International. 


\section{NOUVELLES ACQUISITIONS PATRIMONIALES}

\section{Un recueil de 1626, comprenant trois ouvrages en rapport avec la thématique du temps}

Cette réunion de trois livrets produits par un même imprimeur strasbourgeois, tous trois en rapport avec la thématique du temps, a quelque chose d'exceptionnel. Il s'agit, au moins pour deux d'entre eux, de documents de caractère éphémère, issus des presses de Marx van der Heyden, imprimeur actif à Strasbourg de 1616 à 1637 auprès des graveurs Jacob et Isaac van der Heyden.

Le premier est un calendrier pour l'année 1626 intitulé Schreibkalender, c'est-à-dire calendrier destiné à être support d'écriture. Son organisation est originale : elle fait alterner des colonnes imprimées de calendrier et des espaces laissés libres (pages blanches), destinés à l'écriture personnelle. On peut voir que ces pages blanches sont volontairement insérées ou laissées à ces endroits car l'encre d'imprimerie rouge et noire a laissé des traces sur la page vierge en vis-à-vis. Cette manière d'interfolier est donc bien le dispositif d'origine, destiné à permettre à l'usager de ce livret d'y inscrire ce que bon lui semble. Des annotations ont d'ailleurs été ajoutées sur certains feuillets blancs. Le calendrier se termine sur quelques pages de considérations en rapport avec l'astrologie et les saisons. Une liste des foires et marchés importants clôt l'ouvrage. Son titre exact est Schreibkalender mit der Wetter Practica und newen Messbüchlein nach Christi unsers Seligmachers Geburt MDCXXVI.
Le second ouvrage est un livret de pronostications intitulé Prognosticon astrologicum. Grosse teutsche Practica auff das Jahr nach unsers einigen herzen und Seligmachers jesu Christi geburt gemeiner ublicher rechnung nach MDCXXVI. Au verso de la page de titre figure le nom de l'auteur : Isaac Habrecht. Il s'agit d'une prédiction météorologique, basée sur l'astrologie, pour toute une année. Les éclipses sont également prévues et représentées schématiquement par des petits bois gravés. L'auteur, Isaac Habrecht (deuxième du nom, 1589-1533) était médecin, astronome, astrologue et également constructeur de globes.

Le troisième ouvrage est intitulé Newe Zeyt-Prophetey oder Practica, die Beste, zwischen Himmel und Erden abgemercket von dem Zustandt dess gantzen Jahrs, Aenderung dess Wetters, Verhaltung der Gewächs und des Viehes, dem gemeinen Landmann zu gutem ordentlich beschrieben, und aussgelegt, Auff das Jahr nach unsers Herren und Seligmachers Jesu Christi Geburt 1626. Les auteurs fictifs sont nommés : Veltin Lug ins Land, der Melckereyen und siben guter Kühställ Meyeristen. Dans ce livret, chaque mois est décrit à travers ses conditions atmosphériques et les phases de la lune, annonçant guerres et catastrophes. Dans l'avant-dernier paragraphe il est question des éclipses, et un poème de caractère moralisant sur les semailles clôt le tout.
La couverture d'origine est conservée à l'intérieur d'une reliure plein parchemin du $20^{\mathrm{e}}$ siècle avec inscription calligraphique du titre global donné par un bibliophile récent. La couvrure d'origine du recueil est un papier grossièrement peint en rouge et fortement usagé.

Ces opuscules ne sont pas recensés par le Répertoire bibliographique des livres imprimés en France au XVII siècle, tome VII, Alsace, de Jacques Betz. Cote BNU de l'ensemble : R.105.701.

\section{Daniel Bornemann}




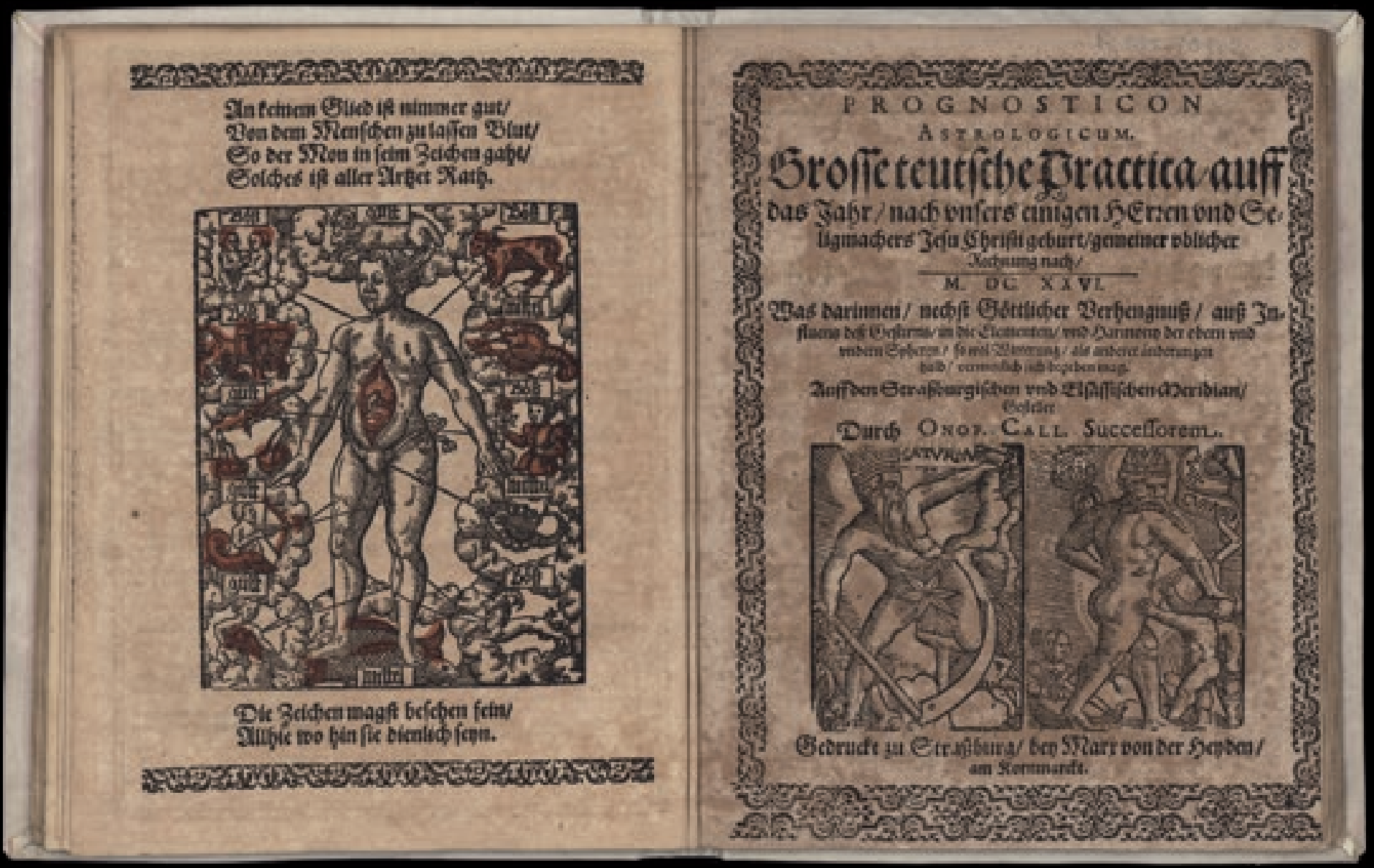

Dernière page du premier ouvrage

et page de titre du second. 